\title{
Exposure to Bisphenolic Analogues in the Sixth Total Diet Study - China, 2016-2019
}

\author{
Jing Zhangi'; Kai Yao ${ }^{1}$; Jie Yin ${ }^{1}$; Bing Lyu'; Yunfeng $\mathrm{Zhao}^{2}$; Jingguang $\mathrm{Li}^{2}$; Bing Shao ${ }^{1, *,}$; Yongning $\mathrm{Wu}^{2, *}$
}

\section{Summary}

What is already known about this topic?

Bisphenol A (BPA) and other bisphenolic compounds (BPs) are proved to pose potential endocrine disrupting properties. The primary source of BP exposure is the diet. European Food Safety Authority (EFSA) established a temporary tolerable daily intake ( $\mathrm{t}$-TDI) of BPA $4 \mu \mathrm{g} / \mathrm{kg}$ body weight per day.

\section{What is added by this report?}

BPs were detected in composite food samples from the Sixth China Total Diet Study (TDS) at percentages of $27.1 \%-78.5 \%$. The estimated dietary exposure of BPA and bisphenol S (BPS) for an average adult were 18.1 $\mathrm{ng} / \mathrm{kg}$ body weight per day and $22.2 \mathrm{ng} / \mathrm{kg}$ body weight per day, respectively. The main dietary contributors for BPs were cereals, water and beverage, meat as well as vegetables.

What are the implications for public health practices?

BP dietary intake poses low risks on the Chinese general population based on the t-TDI set by EFSA. BPS presented a higher exposure level than BPA, which highlights the need to strengthen the surveillance of $\mathrm{BP}$ alternatives in foodstuffs.

Bisphenol A (BPA) is used in the synthesis of commercial plastics, including polycarbonates and epoxy resins, which are incorporated into a wide variety of consumer goods. Exposure to BPA was suspected to result in a variety of toxicities in the neurological, reproductive, metabolic, and immune system (1). Considering these potential undesirable effects, European Food Safety Authority (EFSA) established a temporary tolerable daily intake (t-TDI) of $4 \mu \mathrm{g} / \mathrm{kg}$ body weight per day (2).

Abiding by the regulations on the production and restricted use of BPA in European Union, United States, China, and other countries, BPA in commercial products was gradually replaced by its analogues, such as bisphenol S (BPS), bisphenol F (BPF), bisphenol B $(\mathrm{BPB})$, and bisphenol AF (BPAF). After being put into use, these bisphenolic compounds (BPs) were released into the environment and entered the food chain. A variety of foods (cereals, fruits, meats etc.) were found to contain BPS and other analogues. Studies have shown that the genotoxicity and estrogenic activity of these alternatives are like that of BPA (3-4).

The primary source of exposure to BPA for most people is through the diet from contaminated foodstuffs (5). Dietary exposure of BPA from the Canadian Total Diet Study (TDS) was evaluated in view of BPs in composite food samples (6). In China, BPA from the Fourth China TDS (2007) samples as well as BPA and several analogues from the Fifth China TDS (2010-2012) were analyzed and the estimated daily intakes (EDI) of these BPs were safe for general people (7-8). However, in past decades, China's sustained development and progress have affected the lives of every resident. Under this circumstance, food consumption and contamination levels might have changed remarkably since China's restriction of BPA in baby products and food contact materials implemented since 2011. The purpose of this study was to evaluate the Chinese daily exposure to BPs from the Sixth TDS (2016-2019) (9).

Levels of BPs in the Sixth China TDS were provided in Supplementary Tables S1-S4 (available in https:// weekly.chinacdc.cn/) and summarized in Table 1, where BPA was detected in 216 out of total 288 samples, with a concentration range of non-detected value (ND) to $20.0 \mu \mathrm{g} / \mathrm{kg}$, among which the highest level occurred in cereals from Jiangsu Province. The mean concentrations of BPA from food categories ranged from $0.129 \mu \mathrm{g} / \mathrm{kg}$ (milk) $-1.02 \mu \mathrm{g} / \mathrm{kg}$ (meat). BPS presented a rate of detection of $78.5 \%$, accounting for 226 samples. The maximum level $67.1 \mu \mathrm{g} / \mathrm{kg}$ was attributed to a sample of meats from Fujian Province. While the second largest value is $16.6 \mu \mathrm{g} / \mathrm{kg}$ from a meat sample in Henan Province. BPF and BPAF were found in $8.33 \%$ and $27.1 \%$ of samples, with the maximum concentrations of $1.06 \mu \mathrm{g} / \mathrm{kg}$ and $1.75 \mu \mathrm{g} / \mathrm{kg}$, respectively.

The EDIs of BPA, BPS, BPF, and BPAF for an 
TABLE 1. Occurrence of BPA and its analogues in different composite Total Diet Study samples.

\begin{tabular}{|c|c|c|c|c|c|}
\hline Category & Parameter & BPA & BPS & BPF & BPAF \\
\hline \multirow[t]{4}{*}{ Cereals } & Mean $(\mu \mathrm{g} / \mathrm{kg})$ & 0.466 & 0.545 & 0.007 & 0.012 \\
\hline & Medium $(\mu \mathrm{g} / \mathrm{kg})$ & 0.256 & 0.128 & ND & ND \\
\hline & Range $(\mu \mathrm{g} / \mathrm{kg})$ & ND to 1.44 & ND to 6.40 & ND to 0.169 & ND to 0.129 \\
\hline & Detective rate $(\%)$ & 91.7 & 83.3 & 4.2 & 29.2 \\
\hline \multirow[t]{4}{*}{ Legumes and nuts } & Mean $(\mu \mathrm{g} / \mathrm{kg})$ & 0.484 & 0.984 & 0.146 & ND \\
\hline & Medium $(\mu \mathrm{g} / \mathrm{kg})$ & 0.255 & 0.707 & ND & ND \\
\hline & Range $(\mu \mathrm{g} / \mathrm{kg})$ & ND to 3.39 & ND to 4.23 & ND to1.06 & ND \\
\hline & Detective rate $(\%)$ & 87.5 & 91.7 & 37.5 & 0 \\
\hline \multirow[t]{4}{*}{ Potatoes } & Mean $(\mu \mathrm{g} / \mathrm{kg})$ & 0.340 & 0.163 & 0.008 & 0.006 \\
\hline & Medium $(\mu \mathrm{g} / \mathrm{kg})$ & 0.271 & 0.147 & ND & ND \\
\hline & Range $(\mu \mathrm{g} / \mathrm{kg})$ & ND to 1.35 & ND to 0.648 & ND to 0.186 & ND to 0.029 \\
\hline & Detective rate $(\%)$ & 95.8 & 91.7 & 4.2 & 29.2 \\
\hline \multirow[t]{4}{*}{ Meats } & Mean $(\mu \mathrm{g} / \mathrm{kg})$ & 1.024 & 5.827 & 0.106 & 0.026 \\
\hline & Medium $(\mu \mathrm{g} / \mathrm{kg})$ & 0.476 & 2.010 & ND & ND \\
\hline & Range ( $\mu \mathrm{g} / \mathrm{kg})$ & ND to 5.82 & ND to 67.1 & ND to 0.279 & ND to 0.530 \\
\hline & Detective rate $(\%)$ & 95.8 & 91.7 & 20.8 & 25 \\
\hline \multirow[t]{4}{*}{ Eggs } & Mean $(\mu \mathrm{g} / \mathrm{kg})$ & 0.180 & 0.130 & ND & 0.021 \\
\hline & Medium $(\mu \mathrm{g} / \mathrm{kg})$ & 0.169 & 0.042 & ND & 0.013 \\
\hline & Range $(\mu \mathrm{g} / \mathrm{kg})$ & ND to 0.544 & ND to 0.636 & ND & ND to 0.061 \\
\hline & Detective rate $(\%)$ & 54.2 & 87.5 & 0 & 50 \\
\hline \multirow[t]{4}{*}{ Aquatic foods } & Mean $(\mu \mathrm{g} / \mathrm{kg})$ & 0.927 & 1.25 & 0.015 & 0.125 \\
\hline & Medium $(\mu \mathrm{g} / \mathrm{kg})$ & 0.689 & 0.621 & ND & 0.024 \\
\hline & Range $(\mu \mathrm{g} / \mathrm{kg})$ & 0.199 to 3.31 & ND to 6.34 & ND to 0.192 & ND to 1.75 \\
\hline & Detective rate $(\%)$ & 100 & 95.8 & 8.3 & 79.2 \\
\hline \multirow[t]{4}{*}{ Milk } & Mean $(\mu \mathrm{g} / \mathrm{kg})$ & 0.129 & 0.022 & ND & 0.002 \\
\hline & Medium $(\mu \mathrm{g} / \mathrm{kg})$ & ND & 0.008 & ND & ND \\
\hline & Range $(\mu \mathrm{g} / \mathrm{kg})$ & ND to $<0.385$ & ND to 0.148 & ND & ND to 0.026 \\
\hline & Detective rate $(\%)$ & 41.7 & 29.2 & 0 & 12.5 \\
\hline \multirow[t]{4}{*}{ Vegetables } & Mean $(\mu \mathrm{g} / \mathrm{kg})$ & 0.347 & 0.343 & 0.015 & 0.010 \\
\hline & Medium $(\mu \mathrm{g} / \mathrm{kg})$ & 0.293 & 0.127 & ND & ND \\
\hline & Range $(\mu \mathrm{g} / \mathrm{kg})$ & ND to 1.09 & 0.020 to 1.81 & ND to 0.190 & ND to 0.041 \\
\hline & Detective rate $(\%)$ & 95.8 & 100 & 8.3 & 37.5 \\
\hline \multirow[t]{4}{*}{ Fruits } & Mean $(\mu \mathrm{g} / \mathrm{kg})$ & 1.68 & 0.315 & 0.032 & 0.023 \\
\hline & Medium $(\mu \mathrm{g} / \mathrm{kg})$ & 0.418 & 0.111 & ND & ND \\
\hline & Range $(\mu \mathrm{g} / \mathrm{kg})$ & ND to 20.0 & 0.026 to 1.71 & ND to 0.449 & ND to 0.175 \\
\hline & Detective rate $(\%)$ & 91.7 & 100 & 12.5 & 41.7 \\
\hline \multirow[t]{4}{*}{ Sugar } & Mean $(\mu \mathrm{g} / \mathrm{kg})$ & 0.909 & 0.034 & 0.011 & 0.006 \\
\hline & Medium $(\mu \mathrm{g} / \mathrm{kg})$ & 0.602 & 0.021 & ND & ND \\
\hline & Range ( $\mu \mathrm{g} / \mathrm{kg})$ & 0.197 to 3.26 & ND to 0.114 & ND to 0.260 & ND to 0.043 \\
\hline & Detective rate $(\%)$ & 91.7 & 70.8 & 4.2 & 20.8 \\
\hline \multirow[t]{4}{*}{ Beverages and water } & Mean $(\mu \mathrm{g} / \mathrm{kg})$ & 0.234 & 0.058 & ND & ND \\
\hline & Medium $(\mu \mathrm{g} / \mathrm{kg})$ & ND & 0.013 & ND & ND \\
\hline & Range $(\mu \mathrm{g} / \mathrm{kg})$ & ND to 1.57 & ND to 0.612 & ND & ND \\
\hline & Detective rate $(\%)$ & 20.8 & 50.0 & 0 & 0 \\
\hline \multirow[t]{4}{*}{ Alcoholic beverages } & Mean $(\mu \mathrm{g} / \mathrm{kg})$ & 0.161 & 0.081 & ND & ND \\
\hline & Medium $(\mu \mathrm{g} / \mathrm{kg})$ & ND & 0.012 & ND & ND \\
\hline & Range $(\mu \mathrm{g} / \mathrm{kg})$ & ND to 0.610 & ND to 1.54 & ND & ND \\
\hline & Detective rate $(\%)$ & 37.5 & 50 & 0 & 0 \\
\hline \multirow[t]{3}{*}{ Total } & Mean $(\mu \mathrm{g} / \mathrm{kg})$ & 0.546 & 1.17 & 0.023 & 0.019 \\
\hline & Medium $(\mu \mathrm{g} / \mathrm{kg})$ & 0.251 & 0.055 & ND & ND \\
\hline & Detective rate $(\%)$ & 75.3 & 78.5 & 8.33 & 27.1 \\
\hline
\end{tabular}




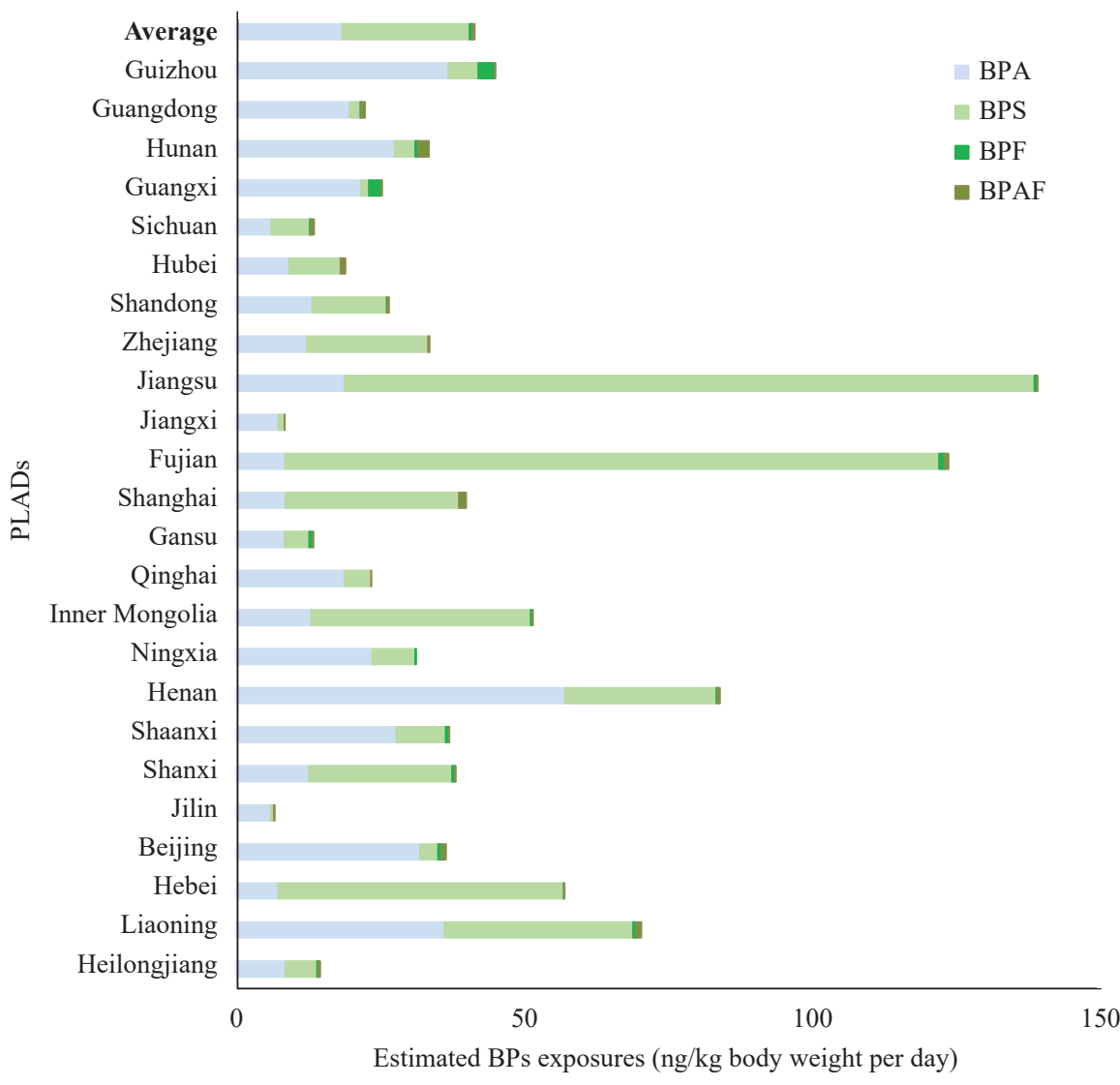

FIGURE 1. EDI of BPA, BPS, BPF, and BPAF among sampling PLADs from the Sixth TDS.

Abbreviations: $B P s=b i s p h e n o l i c$ compounds; $E D I=e s t i m a t e d$ daily intakes; $B P A=b i s p h e n o l ~ A ; ~ B P S=b i s p h e n o l ~ S$; $\mathrm{BPF}=$ bisphenol F; BPAF=bisphenol AF; PLADs=provincial-level administrative divisions; TDS=Total Diet Study.

average male adult are given in Figure 1. For BPA, the highest exposure was found in Henan $(56.9 \mathrm{ng} / \mathrm{kg}$ body weight per day), while the lowest was found in Jilin (5.74 $\mathrm{ng} / \mathrm{kg}$ body weight per day). Mean exposure to BPA was estimated to be $18.1 \mathrm{ng} / \mathrm{kg}$ body weight per day, significantly below the t-TDI $(4 \mu \mathrm{g} / \mathrm{kg}$ body weight per day) recommended by the EFSA (2). The EDI of BPS in the Sixth TDS for an average Chinese male adult was $22.2 \mathrm{ng} / \mathrm{kg}$ body weight per day. Jiangsu (120 ng/kg body weight per day) and Fujian (114 ng/kg body weight per day) posed the two highest exposures in this TDS; while the exposure in Jilin residents $(0.559 \mathrm{ng} / \mathrm{kg}$ body weight per day) was the lowest. BPF and BPAF presented dietary exposures of $0.485 \mathrm{ng} / \mathrm{kg}$ body weight per day and $0.384 \mathrm{ng} / \mathrm{kg}$ body weight per day, respectively.

The contributions of different food categories to total EDI of BPs are shown in Figure 2. The main dietary contributors for BPA were cereals (40.3\%), water and beverage $(17.4 \%)$ as well as vegetables $(13.7 \%)$. As for BPS, the dominant contribution food groups were cereals $(31.4 \%)$, followed by meats
$(25.4 \%)$, legumes $(11.7 \%)$, vegetables $(11.7 \%)$ and water and beverages $(8.76 \%)$. Legumes $(41.2 \%)$, meats $(20.7 \%)$, and fruits $(11.7 \%)$ were the top three contributors of BPF. Exposure to BPAF was mainly from cereals $(22.6 \%)$, aquatic foods $(21.5 \%)$ and vegetables $(21.2 \%)$.

\section{DISCUSSION}

In the Sixth China TDS, BPS posed a comparable rate of detection as BPA, demonstrating the wide use of BPS. Compared to BPA and BPS, BPF and BPAF appeared to possess evidently lower rates of detection and detection levels. Similar trends were found in the Fifth China TDS (8) and several other reports (10-11).

Considering the similar endocrine disrupting properties and other toxicological effects of BPs, the exposure levels of BPA, BPS, BPF, and BPAF were summed up to assess the risks through dietary intake. The combined exposure levels (6.45-139 ng/kg body 


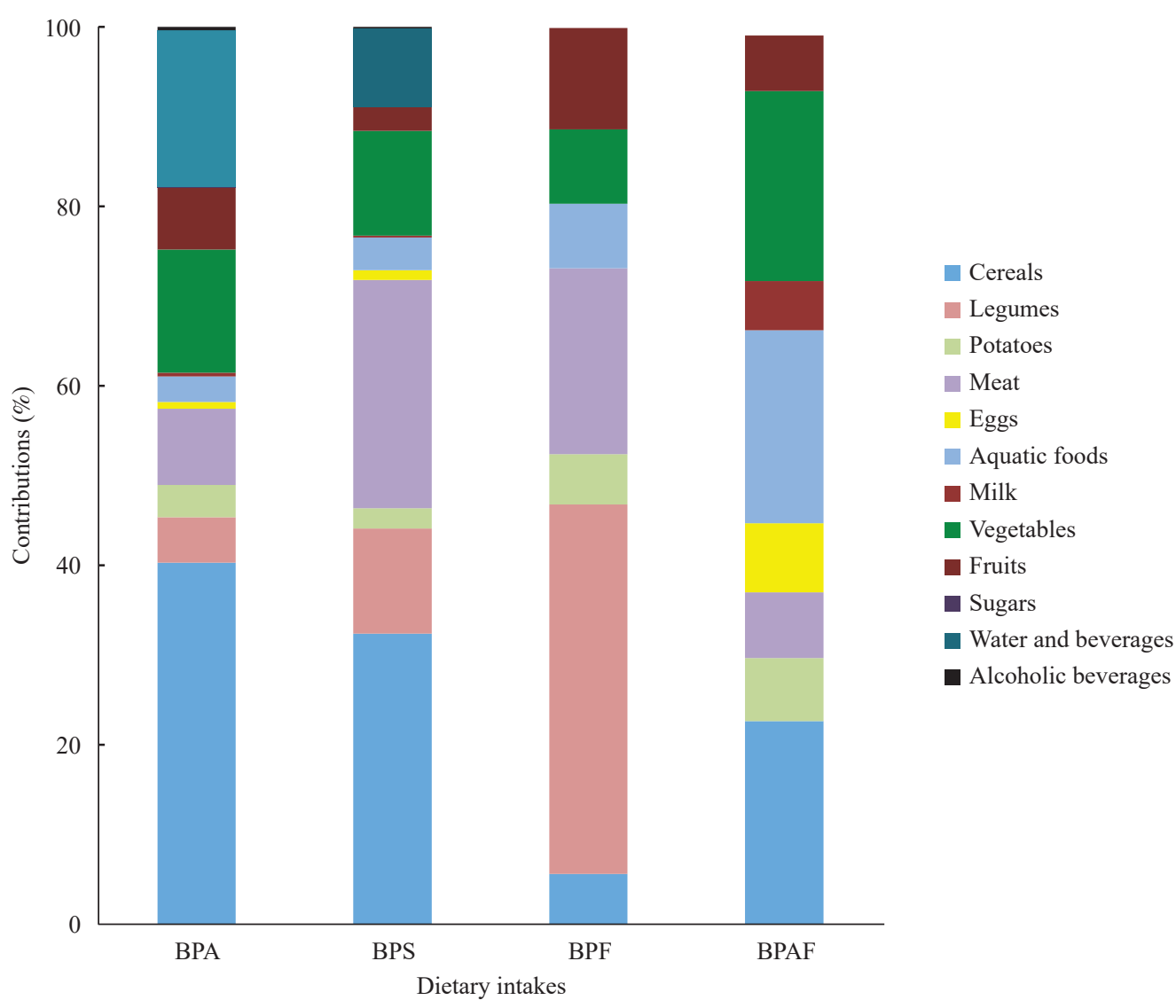

FIGURE 2. Contribution (\% of daily intake) of the food categories to dietary BP intakes for the general Chinese population.

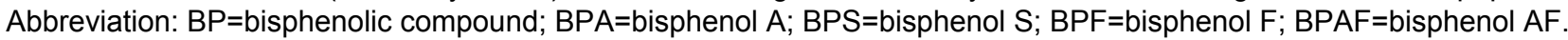

weight per day, Figure 1) were far below the t-TDI of BPA set by EFSA, which implied that the exposure to BPs for Chinese adults was safe.

BPs were concerning in the past three China TDSs (Supplementary Table S5, available in https://weekly. chinacdc.cn/). The BPA exposures in the Fourth and Fifth TDS were $43.0 \mathrm{ng} / \mathrm{kg}$ body weight per day (7 and $217 \mathrm{ng} / \mathrm{kg}$ body weight per day (8), respectively. The increase of BPA exposure might be attributed to the feverish growth of China's BPA consumption from 2000 to 2014. The exposure to BPA in this study was significantly less than that in the Fifth TDS, which may be related to the measures and restrictions of BPA use in China. The exposures to BPS, BPF, and BPAF in the Sixth TDS were also lower than that in the Fifth one.

The most remarkable change was that the exposure to BPS exceeded BPA and became the most dominant $\mathrm{BP}$ in the Sixth TDS. In Fujian and Jiangsu, the only two provincial-level administrative divisions (PLADs) where BPs intakes were higher than $100 \mathrm{ng} / \mathrm{kg}$ body weight per day, BPS contributed more than $80 \%$ of the total BP exposure due to the high levels of BPS in meat from Fujian and cereals from Jiangsu.

It is noteworthy that Jilin implemented the "Restriction on Plastic Bags" from January 1, 2015, stipulating that the production and sale of nondegradable plastic shopping bags and plastic tableware were prohibited throughout the province. It has become China's first PLAD to fully ban "plastics". The EDIs of BPA and BPS in Jilin in this study were $5.74 \mathrm{ng} / \mathrm{kg}$ body weight per day and $0.559 \mathrm{ng} / \mathrm{kg}$ body weight per day, respectively, ranking lowest among the 24 PLADs. These values were lower by more than an order of magnitude than the results in the Fifth TDS $(300 \mathrm{ng} / \mathrm{kg}$ body weight per day for BPA and $11.7 \mathrm{ng} / \mathrm{kg}$ body weight per day for BPS, respectively), indicating that the implementation of the restrictions affected the reduction of BPs contaminants.

The total dietary exposure to BPA in the Sixth China TDS (18.13 ng/kg body weight per day) was lower than that in France $(42.4 \mathrm{ng} / \mathrm{kg}$ body weight per day) (12), Canada (52-81 ng/kg body weight per day) (6), the United States $(44.6 \mathrm{ng} / \mathrm{kg}$ body weight per day) (11), and the EFSA (116-159 ng/kg body weight 
per day) (2). However, it was higher than that of a recent survey in United States $(6.0 \mathrm{ng} / \mathrm{kg}$ body weight per day) (13). The diversity in food consumption habits may be a potential reason for the relatively high BPA exposure to these Western countries.

This study has several limitations. Only composite samples were analyzed for the dietary intake assessment of population in a given region, which could reveal realistic information by virtue of appropriate selection of the composite sample size and retesting of select individual samples. As for the samples with extremely high levels of contamination, the original individual samples can be assessed instead. The estimated BPs intake was based on a standard Chinese male adult (18-45 years). There was a lack of the dietary exposure data of $0-18$ years-old people in this study. Furthermore, young-aged people and pregnant women are prone to be vulnerable to the endocrine disrupting compounds. The chlorinated derivatives of BPA and BPS reported higher estrogenic activity and other potential toxicities. It is necessary to continuously monitor the dietary exposure of the various BPs, including the chlorinated derivatives.

This study investigated the contamination of BPs in composite food samples from the Sixth China TDS during 2016-2019. BPA and BPS were detected in more than $75 \%$ of the food samples. Dietary intakes of BPs for Chinese adults were below the t-TDI, and the major contribution was from cereals, water and beverages, meat, and vegetables. The exposure of BPS in the Sixth TDS exceeded that of BPA. This implies the need to strengthen the monitoring of BPs in foodstuffs.

Conflicts of interest: No conflicts of interest.

Funding: Supported by the National Key Research and Development Program of China (grant number 2017YFC1600500) and CAMS Innovation Fund for Medical Science (CIFMS 2019-I2M-5-024).

\section{doi: $10.46234 / \mathrm{ccdcw} 2022.044$ \\ \# Corresponding authors: Bing Shao, shaobingch@sina.com; Yongning Wu, wuyongning@cfsa.net.cn.}

\footnotetext{
Beijing Key Laboratory of Diagnostic and Traceability Technologies for Food Poisoning, Beijing Center for Disease Prevention and Control, Beijing, China; ${ }^{2}$ NHC Key Laboratory of Food Safety Risk
}

Assessment, China National Center for Food Safety Risk Assessment, Beijing, China.

Submitted: November 29, 2021; Accepted: March 02, 2022

\section{REFERENCES}

1. Almeida S, Raposo A, Almeida-González M, Carrascosa C. Bisphenol A: food exposure and impact on human health. Compr Rev Food Sci Food Saf 2018;17(6):1503 - 17. http://dx.doi.org/10.1111/1541-4337. 12388

2. EFSA Panel on Food Contact Materials, Enzymes, Flavouring and Processing Aids (CEF). Scientific opinion on the risks to public health related to the presence of bisphenol A (BPA) in foodstuffs. EFSA J 2015;13(1):3978. http://dx.doi.org/10.2903/j.efsa.2015.3978.

3. Chen D, Kannan K, Tan HL, Zheng ZG, Feng YL, Wu Y, et al. Bisphenol analogues other than BPA: environmental occurrence, human exposure, and toxicity-a review. Environ Sci Technol 2016;50(11):5438 - 53. http://dx.doi.org/10.1021/acs.est.5b05387.

4. Wan YJ, Huo WQ, Xu SQ, Zheng TZ, Zhang B, Li YY, et al. Relationship between maternal exposure to bisphenol $S$ and pregnancy duration. Environ Pollut 2018;238:717-24. http://dx.doi.org/10. 1016/j.envpol.2018.03.057.

5. Geens T, Goeyens L, Covaci A. Are potential sources for human exposure to bisphenol-A overlooked[J]? Int J Hyg Environ Health 2011;214(5):339-47. http://dx.doi.org/10.1016/j.ijheh.2011.04.005.

6. Cao XL, Perez-Locas C, Dufresne G, Clement G, Popovic S, Beraldin $\mathrm{F}$, et al. Concentrations of bisphenol A in the composite food samples from the 2008 Canadian total diet study in Quebec City and dietary intake estimates. Food Addit Contam: Part A 2011;28(6):791 - 8. http: //dx.doi.org/10.1080/19440049.2010.513015.

7. Niu YM, Zhang J, Duan HJ, Wu YN, Shao B. Bisphenol A and nonylphenol in foodstuffs: Chinese dietary exposure from the 2007 total diet study and infant health risk from formulas. Food Chem 2015;167:320 - 5. http://dx.doi.org/10.1016/j.foodchem.2014.06.115.

8. Yao K, Zhang J, Yin J, Zhao YF, Shen JZ, Jiang HY, et al. Bisphenol A and its analogues in Chinese Total Diets: contaminated levels and risk assessment. Oxid Med Cell Longev 2020;2020:8822321. http://dx.doi. org/10.1155/2020/8822321

9. Lyu B, Li JG, Wu YN. Characterizing the exposome of food safety risk assessment in China. China CDC Wkly 2022;4(9):157 - 60. http://dx. doi.org/10.46234/ccdcw2022.039.

10. Cao XL, Kosarac I, Popovic S, Zhou S, Smith D, Dabeka R. LCMS/MS analysis of bisphenol $S$ and five other bisphenols in total diet food samples. Food Addit Contam: Part A 2019;36(11):1740 - 7. http: //dx.doi.org/10.1080/19440049.2019.1643042.

11. Liao CY, Kannan K. Concentrations and profiles of bisphenol A and other bisphenol analogues in foodstuffs from the United States and their implications for human exposure. J Agric Food Chem 2013;61(19):4655 - 62. http://dx.doi.org/10.1021/jf400445n.

12. Traoré $\mathrm{T}$, Béchaux $\mathrm{C}$, Sirot $\mathrm{V}$, Crépet $\mathrm{A}$. To which chemical mixtures is the French population exposed? Mixture identification from the second French Total Diet Study. Food Chem Toxicol 2016;98:179 - 88. http:/ /dx.doi.org/10.1016/j.fct.2016.10.028.

13. Morgan MK, Clifton MS. Dietary exposures and intake doses to bisphenol A and triclosan in 188 duplicate-single solid food items consumed by US adults. Int J Environ Res Public Health 2021;18(8):4387. http://dx.doi.org/10.3390/ijerph18084387. 


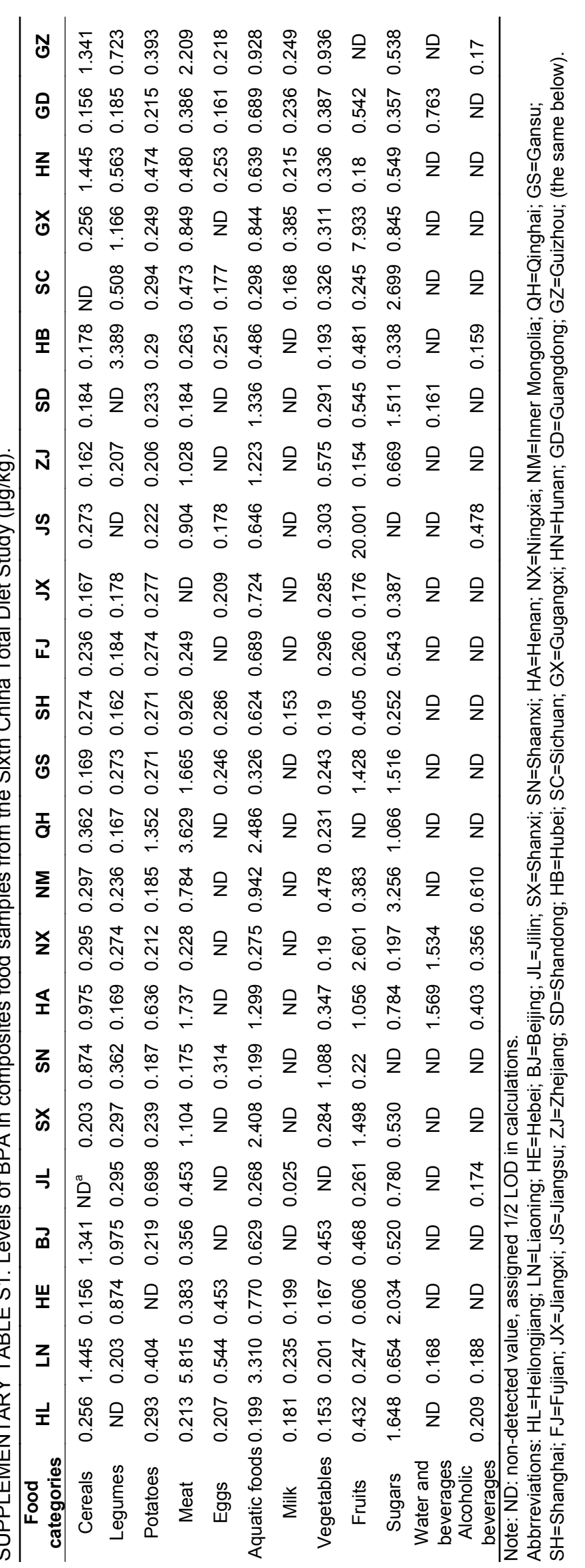

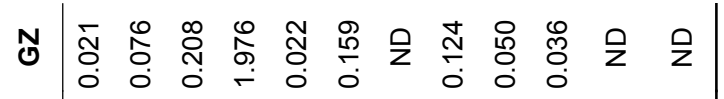

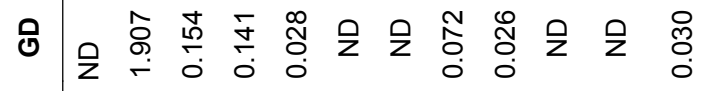

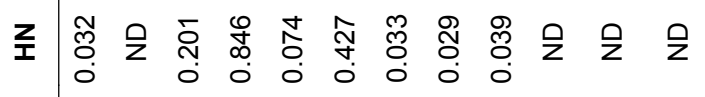

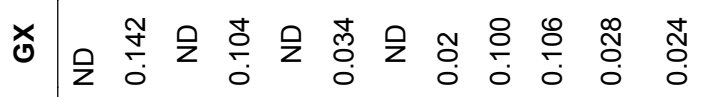

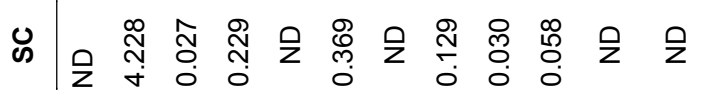

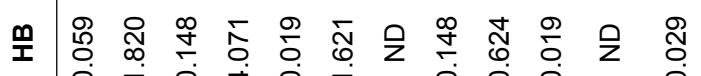

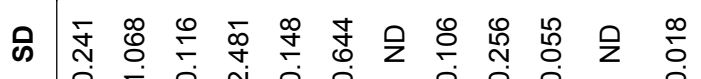

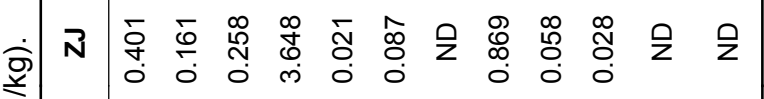
产 总 牙

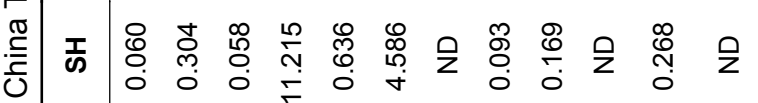
委

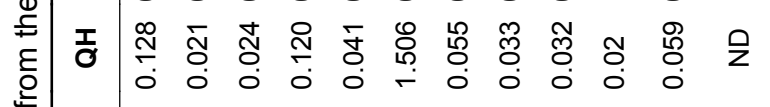

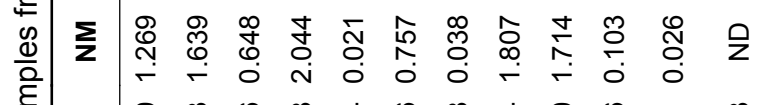

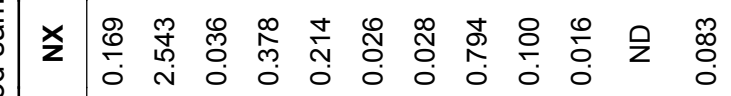

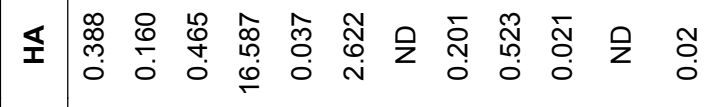

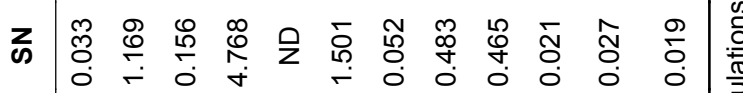

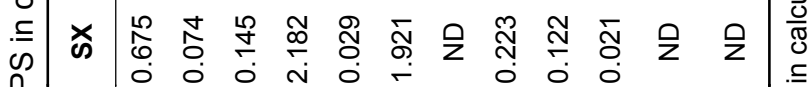
夜

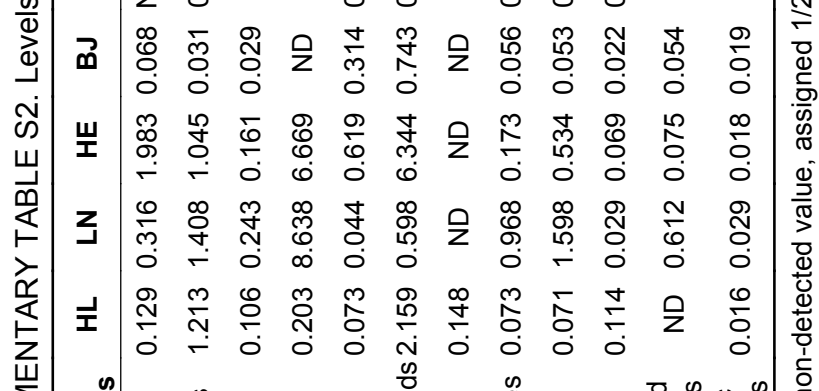

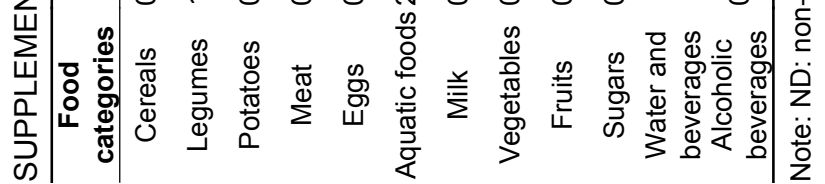




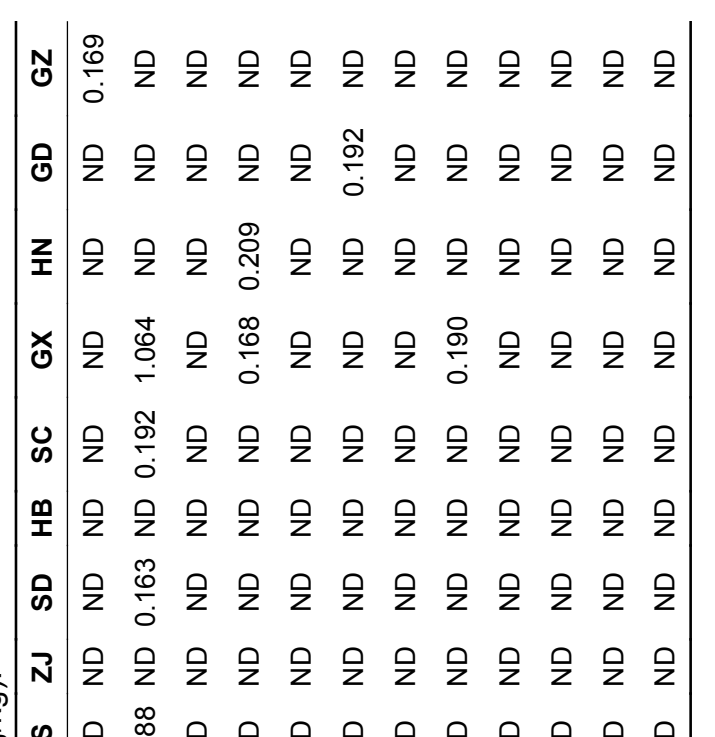

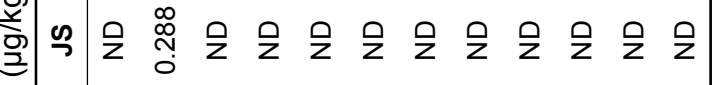

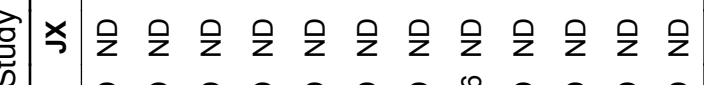
ब) द

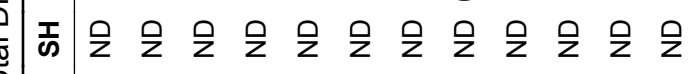
孚

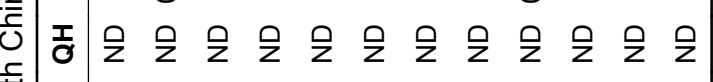

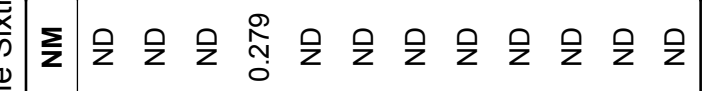
$\stackrel{\oplus}{\equiv}$ 究 $\times$ z 息

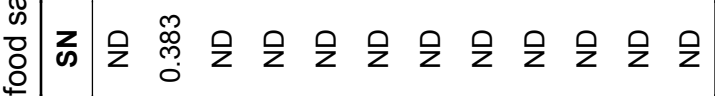
恋 हो 至 峁 离

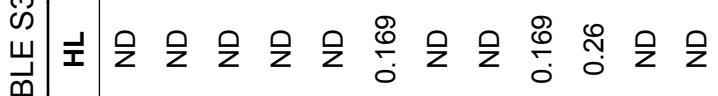

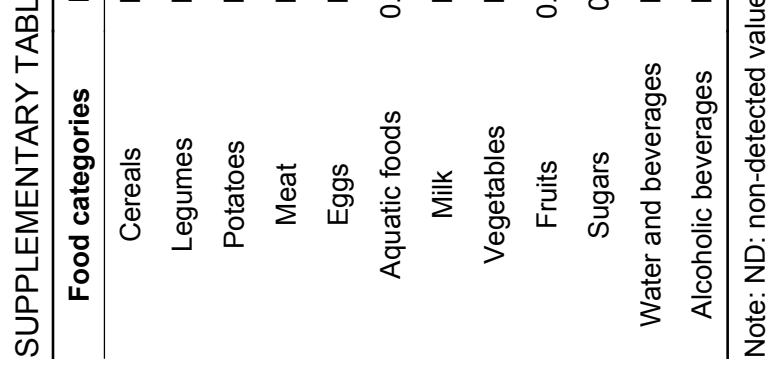

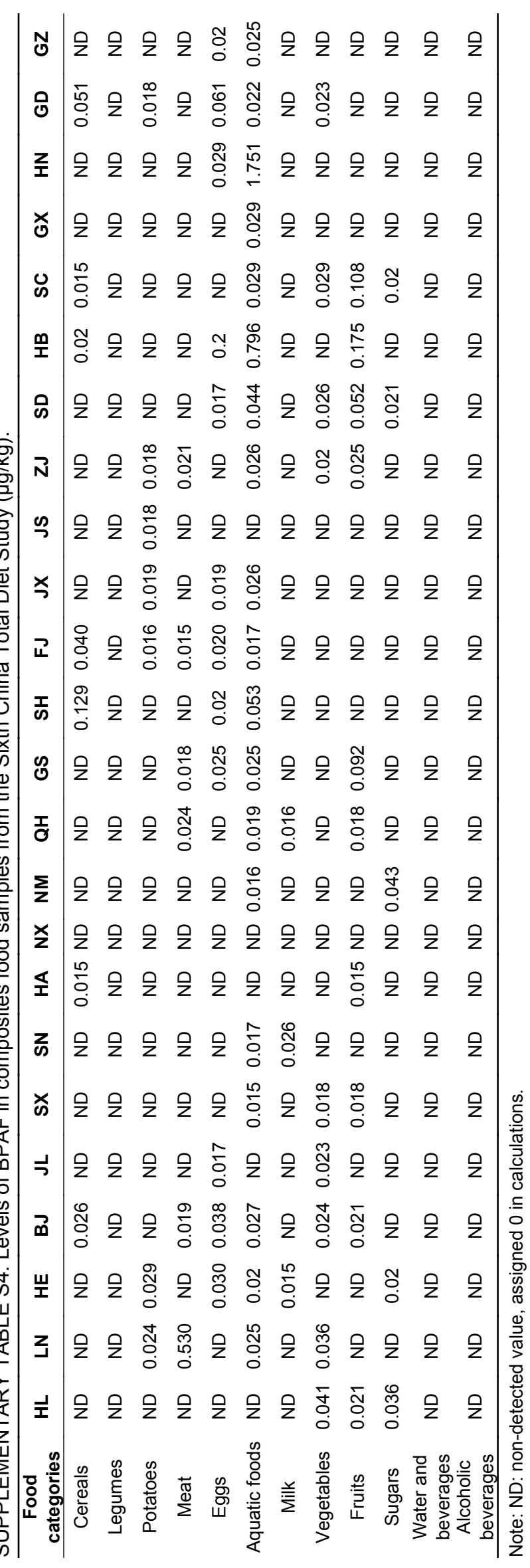


China CDC Weekly

SUPPLEMENTARY TABLE S5. Estimated BPA and its analogues exposures in three Total Diet Studys (ng/kg body weight per day).

\begin{tabular}{cccc}
\hline Compound & The Fourth TDS 2007 & The Fifth TDS 2010-2012 & The Sixth TDS (this study) 2016-2019 \\
\hline BPA & 43 & 217 & 18.1 \\
BPS & - & 25.6 & 22.2 \\
BPF & - & 25.1 & 0.485 \\
BPAF & - & 0.499 & 0.384 \\
\hline
\end{tabular}

Note: "-" means not detected.

Abbrreviations: BPA=bisphenol A; BPS=bisphenol S; BPF=bisphenol F; BPAF=bisphenol AF; TDS=Total Diet Studys. 